\title{
Diseño, aplicación y evaluación de un programa de educación emocional en un centro penitenciario
}

\author{
Filella, G. ${ }^{1}$, Soldevila, A. ${ }^{1}$, Cabello, E. ${ }^{2}$, Franco, $\mathbf{L}^{1}$., \\ Morell, A. ${ }^{3}$, Farré, N. ${ }^{4}$
}

\footnotetext{
${ }^{1}$ Departamento de Pedagogía y Psicología, Universidad de Lleida, Lleida

${ }^{2}$ Maestro en el Centro de formación de personas adultas en el Centro Penitenciario Ponent, Lleida

${ }^{3}$ Subdirectora de Tratamiento del Centro Penitenciario Ponent, Lleida ${ }^{4}$ Psicopedagoga, CEIP Sant Jordi (Oliana), Lleida
}

\section{España}

Gemma Filella Guiu. Facultad Ciencias de la Educación. Universidad de Lleida. C/de l'Estudi General, 4. 25001 Lleida. España. E-mail: gfilella@pip.udl.es.

(C) Education \& Psychology I+D + i and Editorial EOS (Spain) 


\section{Resumen}

Introducción. El propósito de este estudio ha sido evaluar la incidencia que, sobre un grupo de internos de un centro penitenciario, ha tenido la aplicación de un programa de educación emocional para la mejora de la conciencia y la regulación emocional. Se pretendía ofrecer a los internos estrategias de regulación emocional que les fueran útiles en el centro penitenciario y a su vez les facilitaran su futura inclusión social.

Método. Se ha utilizado un diseño cuasiexperimental de grupo único con grupo control. Para medir las variables se utilizaron distintos instrumentos, entre ellos una adaptación del $C E E$ (GROP, 2001), un caso práctico (planteamiento de una situación generadora de emociones negativas), un análisis de las sanciones durante dos meses y un cuestionario de valoración de las actividades del programa por parte de los participantes.

Resultados. Se destaca que la mayoría de ítems del cuestionario aplicado al grupo experimental mejoran después de formarse así como las respuestas dadas en la resolución del caso práctico. Sin embargo no se puede hablar de diferencias significativas en el caso de las sanciones si se compara con el grupo control. También los implicados valoraron positivamente el programa.

Discusión. Los resultados manifiestan que la intervención del programa de educación emocional ha contribuido a la mejora de la conciencia y la regulación emocional del grupo experimental.

Palabras Clave: Programa de educación emocional, conciencia emocional, regulación emocional, internos en centros penitenciarios.

Recibido: 02/04/08 Aceptación Provisional: 22/05/08 Aceptación Definitiva: 29/05/08 


\begin{abstract}
Introduction. The purpose of this study was to evaluate the impact on a group of inmates produced by an educational program to improve emotional awareness and regulation. The program intended to provide emotional regulation strategies which would be useful for them at prison and also for their future social inclusion.
\end{abstract}

Method. A quasi-experimental design of a single experimental group and a control group was used. Different instruments were used to measure the variables, including an adaptation of CEE (GROP, 2001); a practical case (a situation which generates negative emotions), an analysis of sanctions over two months and a questionnaire for participants to assess program activities.

Results. Most of the questionnaire items applied to the experimental group improve after the training as well as answers given to resolve the practical case. However, we cannot say that there are significant differences in sanctions as compared to the control group. Persons participating evaluate the program positively.

Discussion and Conclusion. Results demonstrate that the intervention of an emotional education program contributed toward improving emotional awareness and regulation in the experimental group.

Key words: Emotional education program, emotional awareness, emotional regulation, inmates.

Received: 04/22/08 Initial Acceptance: 05/22/08＿Final Acceptance: 05/29/08 


\section{Introducción}

La mayoría de autores apuntan que los internos de los centros penitenciarios presentan problemáticas relacionadas con la impulsividad, el autocontrol emocional, la atribución causal externa a los acontecimientos, la dificultad para desarrollar pensamiento abstracto, la rigidez conceptual, dificultades para identificar y resolver problemas interpersonales de forma satisfactoria, poca resistencia a la frustración, egocentrismo, baja autoestima, entre otros (Davey et.al., 2005; Filella, 1998; Filella y Blanch, 2002; Liebling y Maruna, 2005; Redondo, 1993 y Valverde, 1991). A partir del análisis de estas necesidades se han desarrollado diversos programas de tratamiento.

Gender y Ross (1979) y Redondo (1993) revisan estudios rigurosos sobre programas de tratamiento para internos en centros penitenciarios y determinaron qué características tenían los más efectivos. Se consideran efectivos los programas que reducen los índices de reincidencia y violencia, además de aquellos cuyos aprendizajes los internos pueden ser transferidos a otros contextos (familiares, formativos, sociales, laborales, etc.). Los programas más eficaces parecen ser aquellos que incluyen técnicas dirigidas a mejorar las habilidades de razonamiento, de empatía, de evaluación de sus conductas hacia los demás y hacia ellos mismos, la reflexión antes de la acción, las habilidades en la resolución de problemas y también de habilidades sociales generalmente poco desarrolladas.

A partir de la explosión científica sobre la inteligencia emocional (Damasio, 1996; Fernández Berrocal, 2006; Ledoux, 1999; Salovey y Mayer, 1990, entre otros) ha ido en aumento la importancia de educar las emociones (Agulló, 2003; Bisquerra, 2003; Justicia et. al., 2006, entre otros), especialmente el control emocional para prevenir y reducir el comportamiento antisocial.

En este sentido se tienen referencias de varios autores que aplican estrategias de regulación emocional para reducir la violencia en los centros penitenciarios. Así, Roger, Derek, Masters y Richard (1997) aplican un programa que incluía el control emocional para reducir la impulsividad de los agresores sexuales y los resultados muestran una reducción significativa de la impulsividad después de la formación, manifiestan actitudes mucho más adaptativas. Howells y Day (2006) afirman que la atención a los factores afectivos en los 
primeros periodos del tratamiento mejora los resultados del mismo en los delincuentes violentos. Greer (2002) también señala la importancia del aspecto emocional en mujeres internas y describe las estrategias de regulación que utilizan en el interior de los centros penitenciarios: distracción conductual, búsqueda espiritual, ejercicios de bloqueo, autorreflexión y humor.

A partir de este marco teórico de referencia nuestro objetivo de investigación ha sido diseñar, implementar y evaluar un programa de educación emocional dirigido a los internos de los centros penitenciarios.

\section{El programa de educación emocional: Conflictos no! Gracias}

En nuestra investigación se ha entendido la educación emocional como un proceso educativo, continuo y permanente que pretende potenciar el desarrollo emocional como complemento indispensable del desarrollo cognitivo, siendo ambos elementos esenciales para el desarrollo de una personalidad integral. Por lo que se propone desarrollar conocimientos y habilidades sobre las emociones a fin de capacitar al individuo para afrontar mejor los retos que le plantea la vida cotidiana. Todo esto tiene como finalidad aumentar el bienestar personal y social (Bisquerra, 2000).

Para el diseño del programa se revisan diversos programas de educación emocional para jóvenes y adultos (Estell et al., 2007; Güell y Muñoz, 2003; Iriarte, Alonso-Gancedo y Sobrino, 2006; Obiols, 2005 y Soldevila, 2007) dado que no se encontraron programas específicos de educación emocional para internos en centros penitenciarios. Finalmente el diseño parte del programa Emociona't para personas mayores de Soldevila (2007).

El programa implementado y evaluado está dirigido básicamente a desarrollar la conciencia y la regulación emocional de los internos del Centro Penitenciario Ponent (LleidaEspaña). 
Los objetivos concretos del programa son: mejorar el conocimiento de las propias emociones, reconocer las emociones en los demás, desarrollar estrategias de regulación emocional, prevenir los efectos perjudiciales de las emociones negativas, desarrollar estrategias para generar emociones positivas, mejorar las habilidades sociales y comunicativas, adoptar una actitud positiva ante la vida, aprender a fluir.

El programa Conflictos, no! Gracias, se estructura en tres bloques temáticos: conciencia emocional, regulación emocional y habilidades sociales y comunicativas. De entre los contenidos desarrollados en el bloque de conciencia se destacan: concepto de emoción, tipología de las emociones, la subjetividad de las emociones, la clasificación de las emociones en positivas, negativas, ambiguas y estéticas, los componentes de las emociones (el neurofisiológico, el comportamental y el cognitivo), entre otros. En relación al bloque de regulación emocional: concepto de regulación emocional, estrategias de regulación emocional (distanciamiento, distracción cognitiva y conductual, aceptar la responsabilidad en los conflictos, actitud positiva, reestructuración cognitiva, relajación, planificación y solución de problemas, buscar ayuda social). Y, finalmente, en el bloque de habilidades comunicativas: estilos de comunicación (pasivo, agresivo y asertivo), derechos de la persona asertiva, técnicas para desarrollar la asertividad, cómo hacer frente a las estrategias de bloqueo de la asertividad.

La metodología utilizada ha sido diversa: lluvia de ideas, philips 6/6, video-forum, dramatización, audiciones musicales, técnicas de relajación, análisis de casos, exposiciones orales, debates, entre otras. La duración del programa ha sido de veinte sesiones, a razón de dos sesiones por semana, y dos horas por sesión.

\section{Método}

\section{Participantes}

La muestra invitada ha sido de 30 internos varones seleccionados al azar (15 para el grupo control y 15 para el grupo experimental) del módulo 6 del Centro Penitenciario de Ponent (Lleida). Hay que destacar una mortalidad de 5 internos en el grupo experimental con lo cual la muestra de estudio ha quedado reducida a 25 sujetos. 
Los internos del módulo 6 están clasificados en segundo grado de tratamiento y se caracterizan por manifestar conductas inadaptadas a la normativa del centro penitenciario de forma reiterativa. Algunos de ellos han salido recientemente del Departamento Especial de Régimen Cerrado ${ }^{1}$ (DERT) y manifiestan pocas relaciones interpersonales positivas, dificultades para la obtención de éxitos educativos y mala trayectoria laboral, elementos que dificultan su futura inserción sociolaboral.

\section{Diseño}

El diseño de la investigación es cuasiexperimental de dos grupos con pretest y postest ya que los internos se encuentran ubicados en el módulo 6 del Centro Penitenciario. La variable independiente es el programa Conflictos, no! Gracias aplicado por dos personas externas al centro (profesoras universitarias) con la colaboración de un profesor del centro penitenciario. Las variables dependientes son la conciencia y la regulación emocional.

\section{Instrumentos de evaluación}

Para la evaluación de la intervención se emplean distintos instrumentos: a) adaptación del cuestionario CEE; b) resolución de un caso práctico; c) análisis de sanciones durante dos meses y d) ficha valorativa del programa por parte de los internos.

a) Se realiza una adaptación del Cuestionario CEE (Álvarez González, 2001). El CEE se considera un instrumento útil en la evaluación de programas emocional. Tiene 68 ítems distribuidos en cinco dimensiones: emociones (conciencia y regulación), autoestima, habilidades sociales, resolución de problemas y habilidades de vida. Para el análisis de la fiabilidad se utilizó el coeficiente alfa de Cronbach para cada una de las dimensiones y los resultados fueron: factor emociones (0.83); autoestima (0.78); habilidades sociales (0.67); resolución de problemas $(0.73)$; habilidades de vida $(0.45)$ y la puntuación total de 0.88 (Álvarez González, 2001: 214).

A partir del CEE se ha elaborado una adaptación que consta de 34 ítems que hacen referencia a la conciencia y a la regulación emocional (dimensión emociones) además de dos

\footnotetext{
${ }^{1}$ En catalán cerrado se traduce por tancat
} 
ítems que tratan la felicidad y el sentido de de la vida (dimensión habilidades de vida). El cuestionario se administra como medida pretest y postest. Las opciones de respuesta van de 0 a 10 entendiendo que 0 es nada y 10 es mucho.

b) Resolución de un caso práctico. Se les plantea una situación como pretest (Estás jugando al parchís y ves que un compañero tuyo hace trampas, tú se lo dices y él te dice que no) y como postest una situación equivalente a la primera (Le dejaste 10 euros a un compañero y hoy tenía que devolvértelos. Cuando le pides el dinero te contesta que no lo tiene (pero tú sabes que es mentira y que no devuelve el dinero porque no quiere). En ambos casos se formulan estas dos cuestiones: ¿qué sientes? y ¿qué harías?

c) Análisis de sanciones durante dos meses. Para valorar la efectividad se comparara el número y el tipo de sanciones que han tenido los internos del grupo experimental con los internos del grupo control dos meses después de haber finalizado la intervención.

d) Ficha valorativa del programa. Una vez concluido el programa se pregunta a los internos acerca del nivel de satisfacción con la formación recibida, sobre la duración de la intervención, sobre aquellos aspectos que cabe mejorar en futuras intervenciones, sobre el profesorado, así como una valoración global.

\section{Resultados}

A) En cuanto a la adaptación del Cuestionario CEE (ver anexo 1) se observa que la mayoría de ítems mejoran después de la formación aunque no todos de forma estadísticamente significativa.

El análisis de la varianza se ha realizado con los ítems del cuestionario medidos en las dos fases (factor repetido) y se ha comparado entre los grupos (factor independiente) muestra los siguientes resultados (TABLA 1). 
TABLA 1. Análisis de la varianza intra fase y entre grupos

\begin{tabular}{llllll}
\hline Ítem & Efecto & $\mathrm{F}$ & g.l. & $\mathrm{n}$ & $\mathrm{p}$ \\
\hline 10 & Fase (intra) & 13.598 & $(1,23)$ & 25 & 0.002 \\
& Grupo (entre) & 3.913 & $(1,23)$ & 25 & 0.068 \\
& Fase*grup & 0.080 & $(1,23)$ & 25 & 0.781 \\
\hline 28 & Fase (intra) & 5.985 & $(1,23)$ & 25 & 0.028 \\
& Grupo (entre) & 0.529 & $(1,23)$ & 25 & 0.479 \\
& Fase*grup & 0.283 & $(1,23)$ & 25 & 0.603 \\
\hline 11 & Fase (intra) & 0.012 & $(1,23)$ & 25 & 0.915 \\
& Grupo (entre) & 0.423 & $(1,23)$ & 25 & 0.526 \\
& Fase*grup & 6.464 & $(1,23)$ & 25 & 0.023 \\
\hline 22 & Fase (intra) & 6.514 & $(1,23)$ & 25 & 0.023 \\
& Grupo (entre) & 0.622 & $(1,23)$ & 25 & 0.444 \\
& Fase*grup & 6.790 & $(1,23)$ & 25 & 0.044 \\
\hline 2 & Fase (intra) & 1.402 & $(1,23)$ & 25 & 0.256 \\
& Grupo (entre) & 4.746 & $(1,23)$ & 25 & 0.047 \\
& Fase*grup & 4.346 & $(1,23)$ & 25 & 0.056 \\
\hline 33 & Fase (intra) & 0.343 & $(1,23)$ & 25 & 0.568 \\
& Grupo (entre) & 4.888 & $(1,23)$ & 25 & 0.044 \\
& Fase*grupo & 0.163 & $(1,23)$ & 25 & 0.693 \\
\hline
\end{tabular}

Por un lado, muestran un cambio significativo en la segunda fase en ambos grupos los ítems $10(\mathrm{p}=0.002)$ en sentido descendente y $28(\mathrm{p}=0.028)$ en sentido ascendente.

Ítem 10: Muchas veces me siento triste sin saber el motivo.

Ítem 28: Tengo claro cuál es el sentido de mi vida

En segundo lugar, los ítems que muestran interacción entre dos factores son el ítem $11(\mathrm{p}=0.023)$ mientras que el grupo experimental aumenta, el grupo control baja. También el ítem 22 ( $\mathrm{p}=0.044)$ donde el control no varia y el experimental aumenta.

Ítem 11: Me fijo mucho en mis propios sentimientos.

Ítem 22: Puedo esperar sin prisas para conseguir lo que deseo.

Por último, se observan diferencias significativas entre los grupos, de forma constante a las dos fases, al ítem $2(\mathrm{p}=0,047)$, donde se aprecia una superioridad del grupo control, y al ítem $33(\mathrm{p}=0.044)$ donde se aprecia que la superioridad es del grupo experimental. 
Ítem 2: Acostumbro a controlarme cuando tengo una emoción fuerte

Ítem 33: Muchas veces me dejo llevar por la rabia y actúo bruscamente

Los ítems que mejoran aunque no significativamente a nivel estadístico del bloque de conciencia son seis $(3,7,8,25,27,30)$; los ítems de regulación emocional son nueve $(4,12,13,16,17,19,21,26,29)$ y el ítem de la felicidad (34).

B) Referente al caso práctico, es decir, al planteamiento de situaciones generadoras de emociones negativas los resultados están descritos en la TABLA 2 y TABLA 3.

TABLA 2. Respuestas de los internos en resolución caso práctico. Medida pretest

\begin{tabular}{lll}
\hline Alumno & ¿Qué sientes? & ¿Qué harías? \\
\hline & Pues me siento muy mal, encima cuando dice que & $\begin{array}{l}\text { Pues lo más seguro que me levantaría y } \\
\text { dejaría de jugar, pero yo como muchas }\end{array}$ \\
O.B. & móstá haciendo trampa pues me mosqueo mucho supuesto eso no pone muy nervioso y & otras personas tengo malos momentos y la \\
& me siento fatal y tampoco me gusta ser tomado podría llegar más lejos. Digo que \\
& por tonto. & $\begin{array}{l}\text { puede ser que podría haber lios } \\
\text { (verbalmente) }\end{array}$ \\
\hline
\end{tabular}

Que por parte de mi compañero va con el equipo

C.B.M. contrario y está haciendo trampas delante de mis No jugar más, cojo y me levanto. narices.

\begin{tabular}{lll}
\hline J.C.R & Me enfado & Me levanto y marcho o bien discuto. \\
\hline M.D & Rabia & $\begin{array}{l}\text { Depende del momento, de cómo esté cada } \\
\text { persona }\end{array}$ \\
\hline J.H.M. & $\begin{array}{l}\text { Rabia, Impotencia y engañado. Incluso ganas de } \\
\text { pelearme. }\end{array}$ & $\begin{array}{l}\text { Levantarme o quedarme y tener que } \\
\text { pelear con él }\end{array}$ \\
\hline A.J.B. & Me enfadaría porque siento enfado y rabia & $\begin{array}{l}\text { No seguir jugando para no agravar mi } \\
\text { rabia }\end{array}$ \\
\hline D.M.M. & Me siento con ira y frustración & $\begin{array}{l}\text { Si no me hace caso no juego más y me } \\
\text { relajo y me voy }\end{array}$ \\
\hline H.R.C. & Rabia, impotencia y engañado & $\begin{array}{l}\text { Pues en el momento no sé; me levantaría y } \\
\text { me iría }\end{array}$ \\
\hline T.S. & $\begin{array}{l}\text { Me siento normal porque es lo que hay aquí, más } \\
\text { trampas que... }\end{array}$ & $\begin{array}{l}\text { Nada, me río y ya está. } \\
\text { acostumbrado a estas cositas, "viva la } \\
\text { libertad” }\end{array}$ \\
\hline M.U.L & Me enfadaría y me irritaría & \begin{tabular}{l} 
Pedirle explicaciones e irme \\
\hline
\end{tabular}
\end{tabular}

Cabe destacar que en el pretest sólo dos internos utilizan terminología específica de emociones, en cambio en el postset todos, menos uno, hablan de rabia. También vemos que en el pretest todos los internos utilizan la conducta pasiva o de evitación del conflicto, mientras que en el postest 6 afirman que utilizarían la respuesta asertiva y tres de ellos utilizarían la estrategia del distanciamiento antes de pedirle que le devuelva el dinero. 
TABLA 3. Respuestas de los internos en resolución caso práctico postest

\begin{tabular}{lll}
\hline Alumno & ¿Qué sientes? & ¿Qué harías? \\
\hline & $\begin{array}{l}\text { Pues nada, por diez euros no merece la } \\
\text { pena buscar una ruina pero lo que haría es }\end{array}$ \\
& cortar todas las relaciones con él y punto; $y$ \\
O.B. & Pues me siento muy mal y jodido, pues fatal. & sione cruarse por mi camino pues ahi \\
& donde creo que hubiera perdido los nervios \\
& y pasaría una tontería, quiero decir que me \\
& enfrentaría físicamente con él.
\end{tabular}

C.B.M. Rabia, impotencia.

\begin{tabular}{ll}
\hline J.C.R & Rabia \\
\hline M.D & $\begin{array}{l}\text { Rabia, impotencia y nunca más le dejaría nada. } \\
\text { Le corto la confianza. }\end{array}$ \\
\hline J.H.M. & Rabia, impotencia, falsedad. \\
\hline & $\begin{array}{l}\text { Siento impotencia, lástima por él pues con esta } \\
\text { actitud demuestra que no es amigo mío, por lo } \\
\text { tanto yo pierdo } 10 \text { euros pero él mucho más. }\end{array}$
\end{tabular}

D.M.M. Rabia e indignación ante su comportamiento.

H.R.C. Rabia, impotencia, falsedad, egoísmo, falta de
palabras.

$\begin{array}{ll}\text { T.S. Siento rabia porque sé que me está engañando. } & \begin{array}{l}\text { Le diré que cuando pueda que me los pague } \\ y \text { nunca más. De todas formas intentaré } \\ \text { recuperar el dinero. }\end{array}\end{array}$

Insistir en que me los dé. Y si no me los da me olvido y que nunca más me pida nada.

Pedirselos por las buenas y si no quiere le daría otra oportunidad para la próxima semana.

No me buscaría problemas, lo dejaría pasar. Dejar pasar tiempo. Intentar dialogar. Mirándole a los ojos le pediría que me contase la verdad; si aún asi me mintiese, lo dejaría correr, le diría que ya me los daría cuando pudiese, pero en realidad no esperaría nada, y no volvería a tratar con él en adelante.

Dialogar a pesar que posiblemente no serviría de nada. Pero no hacer nada más ya que prefiero perder esos 10 euros que responder con violencia que sólo me perjudicaría mucho más perdiendo ciertos beneficios.

Dejar pasar tiempo, calmarse y no volver a prestarle dinero ya que no tiene palabra ni es responsable. recuperar el dinero.

M.U.L No ha contestado

C) En referencia al análisis de sanciones de los dos meses posteriores a la intervención, dos de los internos del grupo experimental han sido objeto de una sanción cada uno. Los motivos de las sanciones son por poseer objetos prohibidos y por desobedecer las instrucciones del funcionario. En el grupo control un interno ha tenido una sanción por desobedecer las instrucciones del funcionario.

En este sentido podemos afirmar que tanto el grupo experimental como el grupo control no indican ningún aumento significativo de hechos sancionables por conductas violentas. 
D) Por último, se pide a los internos que valoren su participación en el programa y las respuestas son las siguientes:

1.- Puntúa entre 1 y 10 el curso de Educación emocional que has realizado. Las puntuaciones obtenidas fueron: Puntuación mínima $=8$ Puntuación máxima $=10 \quad$ Mediana $=9,1$

2.- Valora la duración del curso subrayando la opción que creas más adecuada:

a) Demasiado corto; b) Un poco justo; c) Duración correcta; d) Un poco Largo; e) Demasiado Extenso. Les respuestas fueron: Demasiado corto $=5 \quad$ Un poco justo $=3$ Duración correcta $=2$. Ningún interno ha contestado que el curso ha sido demasiado largo. Se puede afirmar que la mayoría manifiesta que el curso ha estado corto.

3.- ¿Qué has encontrado a faltar en el curso? Las respuestas dadas son:

“Lo único que yo personalmente veo a faltar en el curso es poco tiempo para los que estamos trabajando, quiero decir que dos dias, martes y jueves, es poco tiempo; eso por lo menos me parece a mi”. O.B.

“Más tiempo” C.B.M y M.D.

"Nada porque se hablaba de todo un poco y en algunas cosas me identificaba un poco con mis problemas”. J.C.R.

"Haberlo llevado a la práctica entre nosotros en situaciones imaginarias”. D.M.M

“Más actividades y que nos dejaran trabajos”. H.R.C.

“Falta llegar al fondo. Hacer más ejercicios entre nosotros para ver los fallo”s. T.S.

“No sé qué opinar, todo me pareció bastante bien”. M.U.L.

4.- ¿Qué piensas que ha sobrado o que ha sido demasiado repetitivo?

"Sobrar sí que sobran muchas cosas pero por el contrario algo que ha sido demasiado repetitivo no hay, todo es perfecto”. O.B.

"Que ha sido agradable y he sacado cosas de provecho" C.B.M.

“Nada” J.C.R.; A.J.B y M.U.L.

“Yo pienso que todo estuvo bien”. J.H.M.

"Ha ido mucho mejor de lo que pensaba en un principio. Cambiar el horario" D.M.M.

"Los comentarios de fuera o los ejemplos que nos daban se han repetido". H.R.C. 
“Quizás cambiar el horario (la hora de la siesta es mala)”. T.S.

5.- ¿Valora a los profesores entre 1 y 10? Las puntuaciones obtenidas fueron: Puntuación mínima $=9$ Puntuación máxima $=10 \quad$ Mediana $=9,7$. Los participantes valoran muy satisfactoriamente a los profesores.

6.- ¿Consideras que es un curso interesante? a) Si; b) A medias; c) No. Las respuestas dadas son: Sí = 9 A medias =1. Los alumnos consideran mayoritariamente que el curso ha estado interesante.

7.- ¿Lo recomendarías a tus amistades?: a) Sí; b) A medias; c) No. Las respuestas dadas son: Sí $=9$ A medias $=1$. Los alumnos mayoritariamente recomiendan el curso a sus amistades. Un alumno ha citado que lo recomendaría especialmente a su esposa.

8.- ¿Podrías explicar algún suceso reciente en que hayas aplicado las enseñanzas del curso y los resultados que has obtenido?

"Que por supuesto que sí, que desde que estoy haciendo el curso estoy más tranquilo y pienso más antes de tomar cualquier decisión, más de todo para evitar los problemas que cada día aqui tienes un motivo para tener problemas”. O.B.

“No”. C.B.M y T.S.

"El tener que aguantar a algunos compañeros que antes no los aguantaba y mi forma de pensar sobre algunas cosas, que estaba encerrado en mi mismo y después de algunas sesiones del curso las he visto más claras. J.C.R.

“Todavía no, a no ser que puedo enfocar mejor los problemas y las causas”. D.M.M.

"Tengo un conocido en este lugar que de vez en cuando se siente superior y no respeta, grita a los demás y siempre quiere pelear. Me ha hecho enfadar pero supe controlarme”. H.R.C.

"Pues he aplicado estos métodos a mi relación y he llegado a la valoración de mandar a la mierda a mi pareja por sus impertinencias y sus tonterías con las drogas y sus amigos y he puesto en riesgo otra cosa que es lo que más quiero pero es la mejor: mi hijo con la asistenta para verlo porque no me lo traía”. M.U.L.

9.- ¿Crees que este curso te podrá ayudar en tu vida? a) Sí, seguro que me ayudará; b) Tal vez me ayude c) Es difícil que pueda aplicar algo del curso. Las respuestas dadas son: Sí = 7 
Tal vez $=3$. La mayoría de los alumnos valoran que el curso puede ayudarlos en su vida. Un alumno manifiesta que este curso puede ser interesante hacerlo cuando quede poco tiempo para salir de la cárcel.

10.- Escribe los comentarios o sugerencias que quieras en relación con el curso de Educación emocional

“Que debería haber sido mucho más largo”. C.B.M.

"Yo creo que en el curso se debería tratar unos temas relacionados con los internos y los problemas que tienen". J.C.R.

"Que se aplique todo el material que sea posible y que nos dejen deberes. Que se exija que todos participen en los comentarios”. H.R.C.

"Que quizás estaría muy bien a las personas que les quedase muy poco para salir de la cárcel o quienes salen de permiso”. T.S.

"Que me ha gustado, que ha estado bien y si pudiera lo repetiría”. M.U.L.

\section{Discusión}

Los resultados manifiestan que la intervención del programa de educación emocional Conflictos, no! Gracias ha contribuido a la mejora de la conciencia y la regulación emocional en el grupo experimental.

En cuanto al cuestionario son mayoritarios los ítems que mejoran. Cara a futuras investigaciones cabría comprobar si se mantiene esta tendencia en muestras más amplias y prestar especial atención a aquellos ítems $(3,7,8,25,27,30)$ que mejoran aunque no significativamente del bloque de conciencia al igual que los ítems del bloque de regulación emocional $(4,12,13,16,17,19,21,26,29)$ y al ítem de la felicidad (34).

En cuanto al caso práctico los resultados obtenidos indican que la mayoría de los internos formados parecen tener mejor conciencia de sus emociones y de las emociones de los otros; sabrían regular mejor sus emociones y utilizar más estrategias de regulación emocional. 
En cuanto a las sanciones no se puede concluir que el programa las aumente o las diminuya puesto que tanto en el grupo experimental como en el grupo control las infracciones han sido debidas a la desobediencia a los funcionarios; si es cierto, que en el grupo experimental un interno tenía un objeto prohibido en la celda (bolígrafo para tatuarse), aspecto que no se relaciona directamente con el programa.

Resulta aconsejable pedir la opinión a los internos implicados en el programa mediante técnicas cualitativas pues ayudan a entender qué valor atribuyen a los aprendizajes, a la utilidad de los mismos, la transferencia a otros contextos, etc. En nuestra investigación los datos cualitativos son muy satisfactorios.

Se valora como positivo el hecho que dos personas externas al centro hayan implementado el programa con la colaboración de un profesor del centro penitenciario. Ello permite un feedback con los internos más directo y también aporta información sobre el sistema penitenciario. El profesor era el referente del programa para los internos más allá de las horas de aplicación del programa.

En relación a las limitaciones del estudio cabría diseñar investigaciones con una muestra más amplia y más larga en el tiempo. La información de la que se dispone no es suficiente para poder obtener resultados fiables y estadísticamente significativos. De todas formas, sí que se dispone de información cualitativa que demuestra que el programa ha sido beneficioso, así pues se considera conveniente implementar éste u otros programas de educación emocional en centros penitenciarios.

Para evaluar los efectos del programa sería interesante cara a futuras intervenciones contrarrestar la información con funcionarios, monitores de talleres, educadores, familiares, compañeros de módulo para ver si los efectos del programa se mantienen.

Se concluye que la intervención por programas ha resultado útil y eficaz para la consecución de los objetivos planteados. 


\section{Referencias}

Agulló, M. J. (2003). La educación emocional en el ciclo medio de primaria. Lleida: Universidad de Lleida. (Tesis doctoral inédita).

Álvarez González, M. (2001). Diseño y evaluación de programas de educación emocional. Barcelona: Praxis.

Bisquerra, R. (2000). Educación emocional y bienestar. Barcelona: Praxis.

Bisquerra, R. (2003). Educación emocional y competencias básicas para la vida. Revista de Investigación Educativa, 21 (1), 7-43.

Damasio, A. (1996). El error de Descartes: la emoción, la razón y el cerebro humano. Barcelona: Crítica.

Davey, L. Day, A. y Howells, K. (2006). Affective Determinants of Treatment Engagement in Violent Offenders. International Journal of Offender Therapy and Comparative Criminology, 2, 174-186.

Estell, D.; Farmer, E.; Farmer, T y Hutchins, B. (2007). The development dynamics of aggression and the prevention of school violence. Journal of emotional and Behavioral Disorders, 15, 4.

Fernández-Berrocal, P. y Extremera, N. (2006). Emotional intelligence: A theoretical and empirical review of its 15 years of history. Psicothema, 18 (1).

Filella, G. (1999). La intervención psicopedagógica en el contexto no formal. Lérida: Pagès.

Filella, G. y Blanco L.A. (2002). Imprisonment and career development: an evaluation of a Guidance Program for Job finding. Journal of Career Development, 29(1) .

Gender, P. y Ross, B. (1979). Effective Correctional Treatment: Bibliotherapy for Cynics. Criminal Justice and Behavior, 3, 203-234.

Greer, K. (2002). Walking an emotional tightrope: Managing emotions in a women's prison. Symbolic Interaction, 25 (1) .

Güell M., y Muñoz J. (Coords.). (2003). Educación emocional. Programa de actividades para la Educación Secundaria Postobligatoria. Barcelona: CISSPRAXIS.

Howells, K. y Day, A. (2006). Affective determinants of treatment engagement in violent offenders. International Journal of Offender Rehabilitation and Comparative Criminology, 50, 174-186.

Iriarte, C., Alonso-Gancedo, N. y Sobrino, A. (2006). Relaciones entre desarrollo emocional y moral a tener en cuenta en el ámbito educativo: propuesta de un programa de 
intervención. Electronic Journal of Research in Educational Psychology, 4 (1) 177212

Justicia, F., Benítez, J. L..; Pichardo, M. C.; Fernández, E.; García, T. y Fernández, M. (2006). Aproximación a un nuevo modelo explicativo del comportamiento antisocial. , Electronic Journal of Research in Educational Psychology, 4 (2) 131-150

Ledoux, J. (1999). El cerebro emocional. Barcelona: Ariel.

Liebling, A. y Maruna, S. (2005). The effects of imprisonment. Portland: Willan Publishing.

Obiols, M. (2005). Diseño, desarrollo y evaluación de un programa de educación emocional en un centro educativo de secundaria. Barcelona: Universidad de Barcelona. (Tesis doctoral inédita).

Redondo, S. (1993). Evaluar e intervenir en las prisiones. Barcelona: Promociones y Publicaciones Universitarias.

Roger, D., Masters, R. (1997); The development and evaluation o fan emotion control training programme for sex offenders. Legal and Criminological Psychology, 2 (51-64).

Ross, R., Fabiano, E. y Garrido, V. (1990). El pensamiento prosocial: el modelo cognitivo para la prevención y tratamiento de la delincuencia en Delincuencia, Deliquency, 1, 511.

Salovey, P. y Mayer, J. D. (1990). Emotional intelligence. Imagination, Cognition, and Personality, 9, 185-211.

Soldevila, A. (2007). Diseño, desarrollo y evaluación de un programa de educación emocional para personas mayores. Lleida: Departamento de Pedagogía y Psicología Universidad de Lleida. (Tesis doctoral inédita).

Valverde Molina, J. (1991). La cárcel y sus consecuencias. Madrid: Popular. 


\section{Anexo 1. Cuestionario CEE adaptado \\ CUESTIONARIO DE DESARROLLO EMOCIONAL}

Valora tu grado de desacuerdo o acuerdo con las siguientes cuestiones, marcando el núm. con la siguiente puntuación:

$\begin{array}{rrrrrrrrrr}1 & 2 & 3 & 4 & 5 & 6 & 7 & 8 & 9 & 10 \\ \text { Totalmente en desacuerdo } & & & & & & & & & \text { Totalmente de acuerdo }\end{array}$

\begin{tabular}{|c|c|c|c|c|c|c|c|c|c|c|}
\hline 1.- Conozco bien mis emociones & 1 & 2 & 3 & 4 & 5 & 6 & 7 & 8 & 9 & 10 \\
\hline 2.- Acostumbro a controlarme cuando tengo una emoción fuerte & 1 & 2 & 3 & 4 & 5 & 6 & 7 & 8 & 9 & 10 \\
\hline 3.- Siento vergüenza de muchas cosas que hago & 1 & 2 & 3 & 4 & 5 & 6 & 7 & 8 & 9 & 10 \\
\hline 4.- Me bloqueo cuando tengo que resolver problemas & 1 & 2 & 3 & 4 & 5 & 6 & 7 & 8 & 9 & 10 \\
\hline $\begin{array}{l}\text { 5.- Cuando tengo que hacer algo difícil me pongo nervioso y a veces me } \\
\text { equivoco. }\end{array}$ & 1 & 2 & 3 & 4 & 5 & 6 & 7 & 8 & 9 & 10 \\
\hline 6.- Sé cómo hacer para tener emociones agradables/ positivas & 1 & 2 & 3 & 4 & 5 & 6 & 7 & 8 & 9 & 10 \\
\hline 7.- Sé ponerme en el lugar del otro para comprenderlo bien & 1 & 2 & 3 & 4 & 5 & 6 & 7 & 8 & 9 & 10 \\
\hline 8.- Sé poner nombre a las emociones que tengo & 1 & 2 & 3 & 4 & 5 & 6 & 7 & 8 & 9 & 10 \\
\hline 9.- Me resulta difícil saber cómo se sienten los otros & 1 & 2 & 3 & 4 & 5 & 6 & 7 & 8 & 9 & 10 \\
\hline 10.- Muchas veces me siento triste sin saber el motivo & 1 & 2 & 3 & 4 & 5 & 6 & 7 & 8 & 9 & 10 \\
\hline 11.- Me fijo mucho en mis propios sentimientos & 1 & 2 & 3 & 4 & 5 & 6 & 7 & 8 & 9 & 10 \\
\hline 12.- Me siento responsable de las cosas que me pasan & 1 & 2 & 3 & 4 & 5 & 6 & 7 & 8 & 9 & 10 \\
\hline 13.- Me cuesta relajarme & 1 & 2 & 3 & 4 & 5 & 6 & 7 & 8 & 9 & 10 \\
\hline 14.- Cuando estoy tenso y/o estresado me doy cuenta & 1 & 2 & 3 & 4 & 5 & 6 & 7 & 8 & 9 & 10 \\
\hline 15.- Procuro evitar las actividades que no me gustan & 1 & 2 & 3 & 4 & 5 & 6 & 7 & 8 & 9 & 10 \\
\hline $\begin{array}{l}\text { 16.- Puedo calmarme diciéndome cosas a mi mismo como: } \\
\text { tranquilízate! Respira hondo!... }\end{array}$ & 1 & 2 & 3 & 4 & 5 & 6 & 7 & 8 & 9 & 10 \\
\hline $\begin{array}{l}\text { 17.- Cuando me doy cuenta que he cometido algún error me preocupo } \\
\text { durante mucho tiempo }\end{array}$ & 1 & 2 & 3 & 4 & 5 & 6 & 7 & 8 & 9 & 10 \\
\hline 18.- Me resulta fácil pensar en las consecuencias de mis actos & 1 & 2 & 3 & 4 & 5 & 6 & 7 & 8 & 9 & 10 \\
\hline 19.- Cuando estoy desanimado intento hacer actividades que me gustan & 1 & 2 & 3 & 4 & 5 & 6 & 7 & 8 & 9 & 10 \\
\hline 20.- Me pongo nervioso/a con mucha facilidad y me altero & 1 & 2 & 3 & 4 & 5 & 6 & 7 & 8 & 9 & 10 \\
\hline 21.- Muchas veces tengo problemas con otras personas cercanas a mi & 1 & 2 & 3 & 4 & 5 & 6 & 7 & 8 & 9 & 10 \\
\hline 22.- Puedo esperar sin prisas para conseguir lo que deseo & 1 & 2 & 3 & 4 & 5 & 6 & 7 & 8 & 9 & 10 \\
\hline 23.- Me desanimo cuando alguna cosa me sale mal & 1 & 2 & 3 & 4 & 5 & 6 & 7 & 8 & 9 & 10 \\
\hline 24.- Me cuesta expresar sentimientos cuando hablo con mis amigos & 1 & 2 & 3 & 4 & 5 & 6 & 7 & 8 & 9 & 10 \\
\hline 25.- Estoy satisfecho con mi manera de afrontar la vida & 1 & 2 & 3 & 4 & 5 & 6 & 7 & 8 & 9 & 10 \\
\hline 26.- Por la noche comienzo a pensar y me cuesta dormirme & 1 & 2 & 3 & 4 & 5 & 6 & 7 & 8 & 9 & 10 \\
\hline 27.- Respeto que los otros opinen de forma diferente a mi & 1 & 2 & 3 & 4 & 5 & 6 & 7 & 8 & 9 & 10 \\
\hline 28.- Tengo claro cuál es el sentido de mi vida & 1 & 2 & 3 & 4 & 5 & 6 & 7 & 8 & 9 & 10 \\
\hline 29.- Explico mis problemas a los demás para que me ayuden a resolverlos & 1 & 2 & 3 & 4 & 5 & 6 & 7 & 8 & 9 & 10 \\
\hline 30.- Muchas veces me parece que los otros no entienden lo que les digo & 1 & 2 & 3 & 4 & 5 & 6 & 7 & 8 & 9 & 10 \\
\hline 31.- Me siento herido fácilmente cuando los otros me critican & 1 & 2 & 3 & 4 & 5 & 6 & 7 & 8 & 9 & 10 \\
\hline 32.- Nada de lo que pueda pensar cambiará las cosas que me pasan & 1 & 2 & 3 & 4 & 5 & 6 & 7 & 8 & 9 & 10 \\
\hline 33.- Muchas veces me dejo llevar por la rabia y actúo bruscamente & 1 & 2 & 3 & 4 & 5 & 6 & 7 & 8 & 9 & 10 \\
\hline 34.- Me siento una persona feliz & 1 & 2 & 3 & 4 & 5 & 6 & 7 & 8 & 9 & 10 \\
\hline
\end{tabular}

Muchas gracias por tu colaboración 